\title{
Evaluation of Deuterium-Labeled Internal Standard for the Measurement of Venetoclax by HPLC-ESI -Tandem Mass Spectrometry
}

\author{
Srikanth Inturi ${ }^{*}{ }^{1,2}$, Ratna Kumari Yejerla², Naga Suresh Kumar Jujjuru² ${ }^{2}$ Prameela Rani Avula ${ }^{1}$ \\ 'Department of Pharmaceutical Sciences, University College of Pharmaceutical Sciences, Acharya Nagarjuna University, Guntur, Andhra Pradesh, INDIA. \\ ${ }^{2}$ Department of Pharmaceutical Sciences, Narasaraopeta Institute of Pharmaceutical Sciences, Narasaraopet, Guntur, Andhra Pradesh, INDIA.
}

\begin{abstract}
Objective: Venetoclax is a selective, potent, first-in-class BCL-2 inhibitor that restores apoptosis in cancer cells and has demonstrated clinical efficacy in a variety of haematological malignancies. There is no reported evidence for its measurement in human plasma. Method: A simple, sensitive and specific high-throughput HPLC-ESI-Tandem Mass Spectrometric method was developed for the estimation of Venetoclax (VX) in human plasma using Venetoclax-D8 (VXD8) as an internal standard (IS). Chromatographic separation was performed on Zorbax SB-C18, $75 \times 4.6 \mathrm{~mm}, 3.5 \mathrm{~mm}$, $80 \AA$ column with an isocratic mobile phase composed of Methanol and $5 \mathrm{mM}$ Ammonium acetate in the ratio of $(70: 30 \mathrm{v} / \mathrm{v})$, at a flow-rate of $0.6 \mathrm{~mL} / \mathrm{min}$. The proton adducts of VX and VXD8 were detected at $\mathrm{m} / \mathrm{z}$ $868.12 \rightarrow 321.54$ and $876.9 \rightarrow 329.7$ respectively, using multiple reaction monitoring (MRM) positive mode respectively. The Liquid-Liquid extraction method was used to extract the analyte and IS. Results: The method was successfully validated over linearity concentration range of 10.0-10000.0 $\mathrm{pg} / \mathrm{mL}$ with the correlation coefficient $\left(r^{2}\right) \geq 0.9997$. This method demon-
\end{abstract}

strated intra and inter-day precision within 5.7 to 7.7 and 5.95 to 8.5 and \% Accuracy within 96.3 to 98.7 and 98 to $100.4 \%$. Venetoclax was found to be stable throughout freeze-thawing cycles, bench top, postoperative stability studies. Conclusion: The method was suitable and conveniently applicable to pharmacokinetic and bioavailability studies for estimation of Venetoclax in biological matrices by HPLC-MS/MS

Key words: Deuterium, Pharmacokinetic, Plasma, Proton adduct, Venetoclax. Correspondence

Mr. Srikanth Inturi, University College of Pharmaceutical Sciences, Acharya Nagarjuna University, Nagarjuna Nagar, Guntur, Andhra Pradesh -522510, INDIA.

Phone: +91-9949930493

Email: chrissrikant@gmail.com

DOI: 10.5530/jyp.2018.10.87

\section{INTRODUCTION}

Chronic lymphocytic leukemia (CLL) is the most common form of leukemia in the Western world, representing about 30\% of leukaemias. Venetoclax (ABT-199/GDC-0199) is a highly selective inhibitor of BCL-2 that is more potent than Navitoclax but is less active against BCL-xL by a factor of more than $200 \cdot^{1-3}$

Venetoclax induced apoptosis in-vitro against primary CLL cells and displayed efficacy in vivo in xenograft models of human lymphoid tumors that over expressed BCL-2, with minimal effects on platelets. ${ }^{4-8}$ It selectively binds with high affinity to BCL-2 and with three orders of magnitude less affinity to other BCL-2 family protein members. Venetoclax has been studied in multiple clinical trials and has shown efficacy as a single agent and as combination therapy in patients with relapsed CLL or small lymphocytic lymphoma (SLL) and other hematological malignancies. ${ }^{9-11}$ In vitro studies showed that Venetoclax is metabolized primarily by CYP 3A4, consistent with observations from drug-drug interaction studies with Ketoconazole, Posaconazole and Rifampin. ${ }^{12-13}$

Venetoclax has very low aqueous solubility. Venetoclax is described chemically as 4-(4-\{[2-(4-chlorophenyl)-4,4dimethylcyclohex-1-en-1yl]methyl $\}$ piperazin-1-yl)-N-(\{3-nitro-4 [(tetrahydro-2H-pyran-4ylmethyl)amino]phenyl sulfonyl)-2-(1H-pyrrolo[2,3-b]pyridin-5-yloxy) benzamide) (Figure 1). It is a light yellow to dark yellow solid with the empirical formula $\mathrm{C}_{45} \mathrm{H}_{50} \mathrm{ClN}_{7} \mathrm{O}_{7} \mathrm{~S}$ and a molecular weight of 868.44
Screening of the literature disclosed few published reports for the quantification of Venetoclax concentration in human plasma LC-MS/MS. ${ }^{14}$ We observed so many difficulties with the reported methods in terms of reproducibility and stability for long run analysis, prolonged retention time and moreover matrix interferences.

Selected-ion monitoring (SRM) mode used to detect only the precursor ion in single-quadrupole mass spectrometry. But in our investigation, for the detection of both the precursor and fragment ion using a triplequadrupole mass spectrometry (HPLC-MS/MS) with multiple reaction monitoring (MRM) mode. It shows high specificity.

From the literature review it was concluded that the developed methods shows poor sensitivity, long retention time, lack of deuterated internal standard by using HPLC-ESI-MS/MS.

The purpose of present investigational study is to develop a simple, sensitive, selective, rapid, rugged, reproducible and high throughput HPLCESI-MS/MS method for quantitative measurement of VX using deuterium Isotope labeled internal standard as per US-FDA guidelines. ${ }^{15}$

\section{MATERIALS AND METHODS}

\section{Chemicals and Reagents}

Venetoclax (VX) (AbbVie, Inc. (North Chicago, IL), Venetoclax-D8 (VXD8) (Champchem, China), diethyl ether, methanol (J.T. Baker USA), Potassium dihydrogen phosphate, ammonium acetate (Merck 
Limited, Worli, Mumbai). Ultra pure water (Milli-Q system, Millipore, Bedford, MA, USA), Screened human plasma (Navjeevan blood bank, Hyderabad, A.P). The chemicals and solvents were used in this study analytical and HPLC grade.

\section{Instrumentation}

An API 4000 HPLC-ESI-MS/MS system (Applied Biosystems), 1200 Series HPLC system (Agilent Technologies, Waldbronn, Germany), data acquisition and processing were accomplished using Analyst ${ }^{\oplus}$ Software 1.4.1. Micro balance (ME5 model Sartorius), variable range micro pipette (Eppendorf), Autosampler vials (Agilent), variable size glass bottles, graduated measuring cylinders, volumetric flasks (Borosil), ultrasonic bath (Pharmatek Scientifics), Vortexer (Spinix), deep freezer $\left(-30^{\circ} \mathrm{C}\right.$ Sanyo), nitrogen evaporator (Turbo Vap LV Caliper Life Sciences), refrigerator (LG). Pipette tips $10 \mu \mathrm{L}-1000 \mu \mathrm{L}$, ria vials, $12 \times 7.5 \mathrm{~mm}$ (Tarson) polypropylene tubes; combitips (Eppendorff) and variable size surgical gloves (Surgicare) were employed in the present investigation.

\section{Detection of Mass parameters}

The pure drug of VX and its internal standard VXD8 were prepared in methanol $(10.00 \mathrm{ng} / \mathrm{mL})$ and injected with a flow rate of $5 \mu \mathrm{L} / \mathrm{min}$ into positive ion mode mass spectrometer for optimization of mass parameters like source temperature, IS, heater gas, nebulizer gas, curtain gas, Collision Activated Dissociation (CAD) gas (all gas channels were purged with ultra high pure nitrogen gas), Entrance Potential (EP), Declustering Potential (DP), Collision Energy (CE), Focusing Potential (FP) and Collision Cell Exit Potential (CXP) were optimized. Analysis was performed using MRM positive ion mode with mass transitions of $\mathrm{m} / \mathrm{z}$ (amu) $868.12 \rightarrow 321.54$ and $876.9 \rightarrow 329.7$ for VX and VXD8 respectively.

\section{Chromatographic conditions}

Chromatographic separation was done using Zorbax SB analytical column $(\mathrm{C} 18,3.5 \mu \mathrm{m}, 80 \AA, 75 \mathrm{x} 4.6 \mathrm{~mm})$ at $40^{\circ} \mathrm{C}$. Methanol and $5 \mathrm{mM}$ ammonium acetate in the ratio of $(70: 30 \mathrm{v} / \mathrm{v})$ was used as mobile phase at a flow rate of $0.6 \mathrm{~mL} / \mathrm{min}$. Deuterated internal standard Venetoclax-D8 was used as appropriate internal standard in terms of chromatography and extractability. Venetoclax and Venetoclax-D8 was eluted at $6.1 \mathrm{~min}$ with a total run time of $13 \mathrm{~min}$ for each sample.

\section{Preparation of standards and quality control (QC) samples}

Stock solution of VX $(100.00 \mu \mathrm{g} / \mathrm{mL})$ VXD8 $(100.00 \mu \mathrm{g} / \mathrm{mL})$ were prepared in methanol. The internal standard spiking solution $(30.00 \mathrm{ng} / \mathrm{mL})$ was prepared in 50\% methanol from VXD8 stock solution. Stock solutions and intermediate spiking solutions were stored in refrigerated conditions $\left(2-8^{\circ} \mathrm{C}\right)$ until analysis. Calibration Standards (10.00, 20.00, 200.00, $800.00,1500.00,3000.00,4500.00,6000.00,7500.00$ and $10000.00 \mathrm{pg} / \mathrm{mL}$ ), quality control samples of lower limit QC, low QC, mid QC, high QC $(10.00,30.00,3500.00$ and $8000.00 \mathrm{pg} / \mathrm{mL})$ were prepared by spiking the appropriate amount of standard solution in the drug free plasma and stored at $-30^{\circ} \mathrm{C}$ till analysis.

\section{Sample preparation}

Various organic solvents and buffers were optimized to extract analytes and internal standard from the human plasma sample. After a series of trials, $10 \mathrm{mM}$ potassium dihydrogen phosphate buffer were selected as appropriate due to high recovery efficiency and matrix free interference. Liquid-Liquid extraction (LLE) method was used to isolate Venetoclax and Venetoclax-D8 from human plasma. For this, to each labelled polypropylene tube $50 \mu \mathrm{L}$ of IS $(30.00 \mathrm{ng} / \mathrm{mL})$ was mixed with the $100 \mu \mathrm{L}$ respective concentration of plasma sample, then $100 \mu \mathrm{L}$ of $10 \mathrm{mM}$ potas- sium dihydrogen phosphate buffer and $2.5 \mathrm{~mL}$ of methyl tertiary butyl ether were added, vortexed for $5 \mathrm{~min}$ and centrifuged at $4000 \mathrm{rpm}$ for $10 \mathrm{~min}$ at $20^{\circ} \mathrm{C}$. The organic phase was transferred to a clean PP tube and dried with nitrogen gas at $40^{\circ} \mathrm{C}$. The residue was reconstituted with $200 \mu \mathrm{L}$ reconstitution solution (methanol: $5 \mathrm{mM}$ ammonium acetate $(70: 30 \mathrm{v} / \mathrm{v})$ and injected into the HPLC-ESI-MS/MS for separation analysis.

\section{Method validation}

To confirm the reliability of the proposed method, validation assays were fulfilled according to the U.S. Food and Drug Administration (FDA) Guidance for Industry (Bio analytical Method Validation). The method was validated for selectivity, sensitivity, matrix effect, linearity, precision and accuracy, recovery, reinjection reproducibility and stability.

\section{Selectivity and Sensitivity}

Ten lots of blank plasma samples were analyzed out of which six lots free from interference were selected for assessing the selectivity and specificity. The endogenous/potential interfering peak areas for blank samples must be less than $20 \%$ of the LLOQ peak area of VX retention time and no greater than 5\% for VXD8 retention time.

\section{Linearity}

The analytical curves were constructed using concentrations ranging from $10.0-10000.0 \mathrm{pg} / \mathrm{mL}$ of VX in human plasma. The peak area ratio of (VX/VXD8) versus area response of analyte (VX) concentration in $\mathrm{pg} / \mathrm{mL}$. Calibration curve was obtained by linear model with weighted $1 / \mathrm{x}^{2}$ regression analysis.

\section{Precision and Accuracy}

Four different concentrations of quality control standards of Lower limit QC, Low QC, Mid QC and High QC concentrations (10.0, 30.0, 3500.0 and $8000.0 \mathrm{pg} / \mathrm{mL}$ ) as a set, prepared in screened plasma and analyzed each quality control (QC) standards in six replicates on the same day (Intraday) and five different days (Interday).

\section{Matrix effect}

Six lots of blank biological matrices were extracted each in triplicates and post spiked with the aqueous standard at the mid QC level, and compared with aqueous standards of same concentration. The overall precision of the matrix factor is expressed as relative standard deviation (\%RSD).

\section{Recovery}

The extraction recovery of Analyte and IS from human plasma was determined by analyzing quality control samples. Recovery at three different concentrations $(30.00,3500.00$ and $8000.00 \mathrm{pg} / \mathrm{mL})$ was determined by comparing peak areas obtained from the plasma sample, and the standard solution spiked with the blank plasma residue. A recovery of more than $50 \%$ was considered adequate to obtain required sensitivity.

\section{Limit of Quantification}

Six LLOQ standards were prepared in screened plasma lot along with IS and signal to noise ratio $(\mathrm{S} / \mathrm{N})$ was calculated using analyst software.

\section{Stability studies}

VX Stability in plasma samples done at each level of six aliquots for lower and higher concentrations as per US FDA guidelines. 


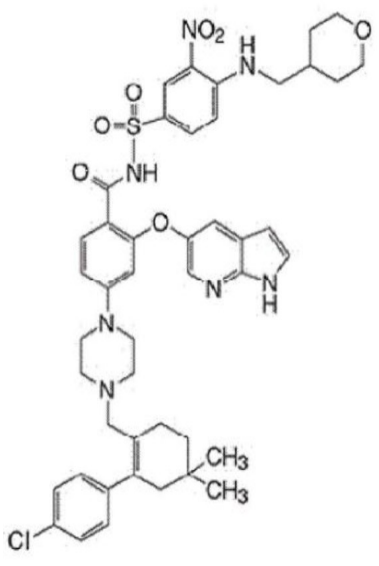

A

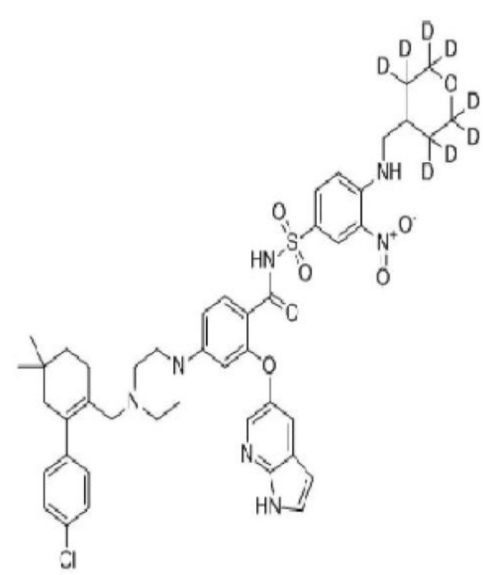

B

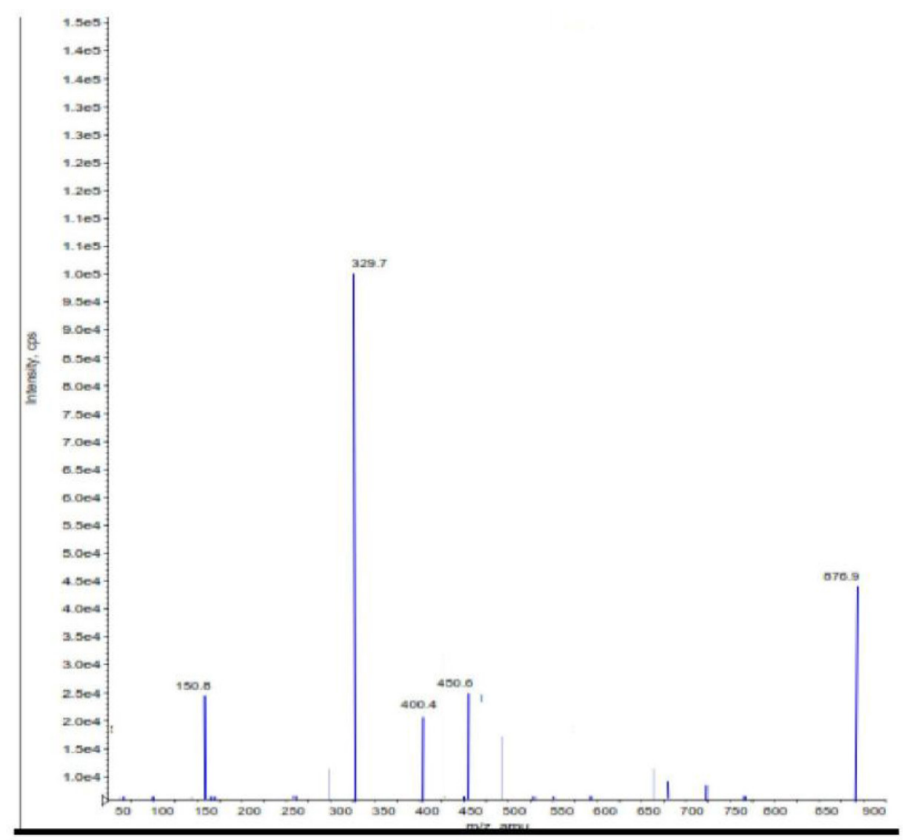

Figure 1: Chemical structures of A) Venetoclax B) Venetoclax-D8.

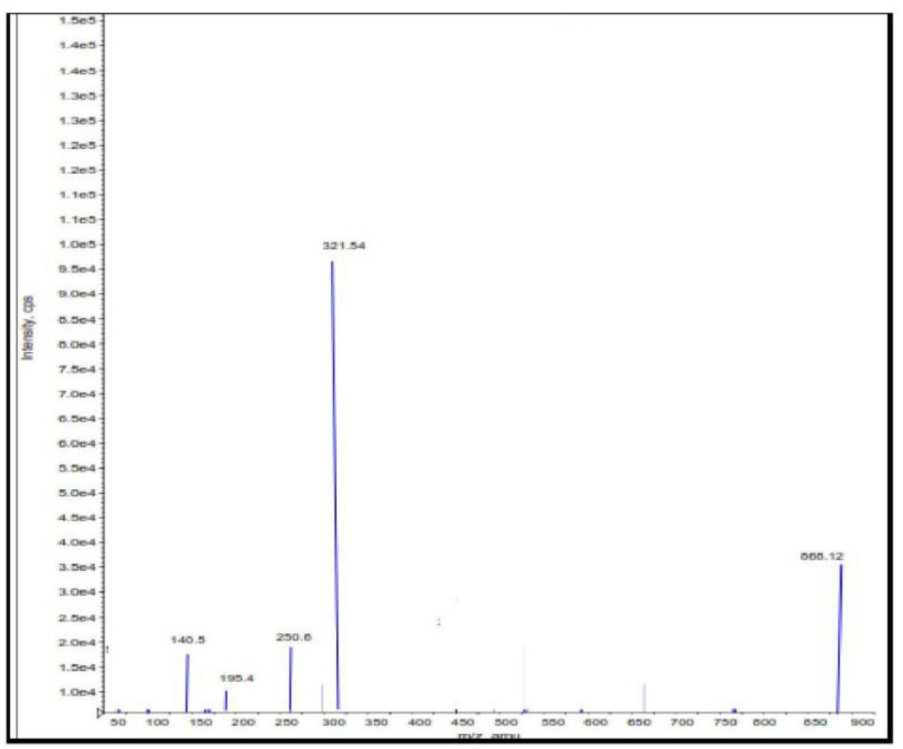

Figure 2: Parent and product ion mass spectra (Q1 and Q3) of VX.

\section{Bench top stability (72 h)}

Six replicates of spiked low and high concentrations were set aside at ambient temperature up to $72 \mathrm{~h}$. Samples were processed and compared with newly prepared low and high concentrations.

\section{Freeze and thaw stability (after $3^{\text {rd }} \mathrm{cycle}$ at $-30^{\circ} \mathrm{C}$ )}

Six replicates of low and high concentrations were frozen at $-30^{\circ} \mathrm{C}$ and subjected to three freeze-thaw cycles of 24,36 and $48 \mathrm{~h}\left(-30^{\circ} \mathrm{C}\right.$ to room temperature) and compared with newly prepared low and high concentrations.

Figure 3: Parent and product ion mass spectra (Q1 and Q3) of VXD8.

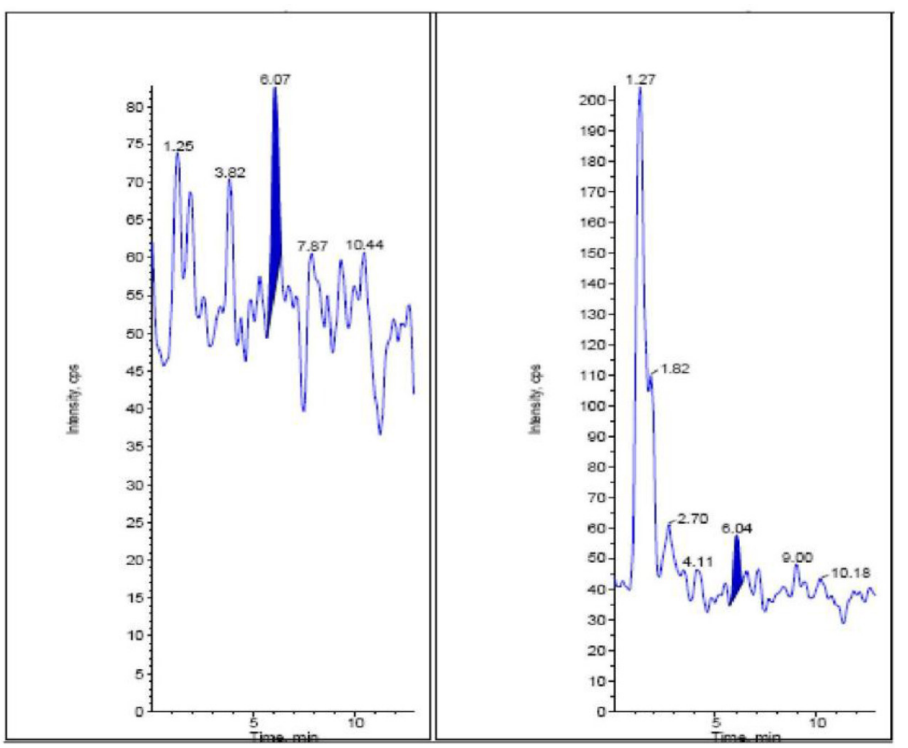

Figure 4: Blank plasma chromatogram of interference free VX and VXD8.

\section{Autosampler stability $\left(2-8^{\circ} \mathrm{C}, 78 \mathrm{~h}\right)$}

Six replicates of low and high concentrations were stored in auto-sampler up to $78 \mathrm{~h}$ at $2-8^{\circ} \mathrm{C}$. Stability samples were compared with newly prepared low and high concentrations.

\section{Long-term stability $\left(-30^{\circ} \mathrm{C}, 71\right.$ Days)}

After completion of the stability period stored at $-30^{\circ} \mathrm{C}$ (71 days) six replicates of low and high concentrations were compared with newly prepared low and high concentrations. 


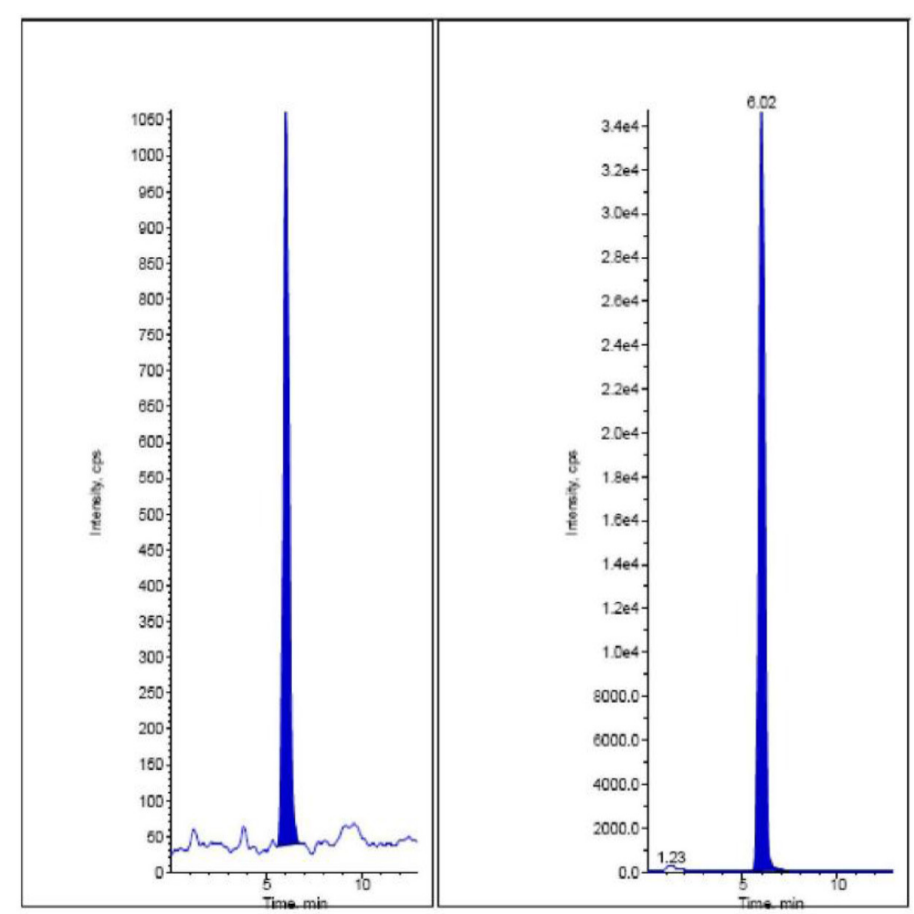

Figure 5: Chromatogram of LOQ sample (VX and VXD8).

\section{RESULTS}

\section{Method validation Selectivity and Specificity}

It was very essential to certify that the signals measured were related only to the analyte and IS. Selectivity of the method was examined by analyzing blank human plasma from six different sources using the selected extraction procedure and HPLC-MS/MS conditions. Chromatograms showed that the method was able to discriminate the analyte, IS from all potential interfering substances. Chromatograms obtained from plasma spiked with VX and VXD8 were depicted in Figure 4 and 5

\section{Linearity}

Calibration curve was determined by plotting the peak area ratios of analyte to IS versus the nominal concentrations of VX. Calibration standards were prepared to obtain good linearity range of 10.0, 20.0, $200.0,800.0,1500.0,3000.0,4500.0,6000.0,7500.0$ and $10000.0 \mathrm{pg} / \mathrm{mL}$ and assayed in five replicates on five different days. The calibration curve had a coefficient correlation $\left(\mathrm{r}^{2}\right)$ was $>0.9997$. The results were depicted in Table 2.

\section{Matrix effect}

Six lots of blank biological matrices were extracted each in triplicates and post spiked with the aqueous standard at the mid-QC level $(3500.0 \mathrm{pg} / \mathrm{mL})$, and compared with neat standards of same concentration in alternate injections. There was no ion suppression and ion enhancement effect observed due to IS and analyte at respective retention time. The overall precision of the matrix factor is expressed as Relative Standard Deviation (\%RSD) and was determined to be 4.32 for VX.

\section{Recovery}

The recovery following the sample preparation using Liquid-Liquid extraction method with $10 \mathrm{mM}$ Potassium dihydrogen phosphate and methyl tertiary butyl ether was calculated by comparing the peak area ratios of VX in plasma samples with the peak area ratios of solvent samples and was estimated at control levels of VX. The extraction recovery was determined in sextuplicate by comparing the extracted QC standards with un-extracted QC standards at three different concentrations of low $(30.00 \mathrm{pg} / \mathrm{mL})$, medium $(3500.00 \mathrm{pg} / \mathrm{mL})$, high $(8000.00 \mathrm{pg} / \mathrm{mL})$ and $99.24,94.79$ and $94.24 \%$ respectively. The overall mean recovery of VX and VXD8 was found to be $96.0 \pm 2.8$ and $98.76 \pm 4.47$ respectively.

\section{Precision and Accuracy}

The results of spiked plasma samples in three consecutive runs were used to evaluate the accuracy and precision. Six replicate samples containing known amount of Venetoclax (30.0, 3500.0 and $8000.0 \mathrm{pg} / \mathrm{mL}$ ) were prepared and analyzed along with each calibration curve as shown in (Table 3). Concentrations were determined by back-calculation of peak area ratios from the corresponding calibration curve. The Intra batch (Within-run) precision and accuracy were between 5.7 to 7.7 and 96.3 to 98.7\% similarly Inter batch (Between-run) Precision and Accuracy were between 5.95 to 8.5 and 98 to $100.4 \%$.

\section{Limit of quantification (LOQ)}

No significant response was observed at retention times of VX and VXD8 in blank plasma as compared to LLOQ and blank with IS samples. The limit of quantification for this method was proven as the lowest concentration of the calibration curve which was proven as $44.12 \mathrm{pg} / \mathrm{mL}$.

\section{Stability (freeze-thaw, auto sampler, bench top, long term)}

Quantification of the VX in plasma subjected to 3 freeze-thaw $\left(-30^{\circ} \mathrm{C}\right.$ to room temperature) cycles showed the stability of the analyte. No significant degradation of the VX was observed even after $78 \mathrm{~h}$ storage period in the autosampler tray and the \% accuracy of VX was between 93.62 to $111.78 \%$ of the theoretical values. Room temperature stability at $72 \mathrm{~h}$ was between 98.2 to $114 \%$ of the theoretical values. In addition, the long-term stability of VX in QC samples after 71 days of storage at $-30^{\circ} \mathrm{C}$ was also evaluated. The \% accuracy ranged from 104.6 to $110 \%$ of the theoretical values. These results confirmed the stability of VX in human plasma for at least 71 days at $-30^{\circ} \mathrm{C}$

\section{DISCUSSION}

During method development, different options were arised and evaluated to optimize chromatography conditions, sample extraction procedures and mass spectrometry detection parameters. On the way to develop a simple and easy applicable method for the measurement of VX in human plasma, HPLC-MS/MS was selected as the method of choice. Initially, a mobile phase consisting of ammonium acetate and acetonitrile in varying combinations was tried, but a low response was observed. The mobile phase containing $10 \mathrm{mM}$ ammonium acetate: acetonitrile $(20: 80 \mathrm{v} / \mathrm{v})$ and $10 \mathrm{mM}$ ammonium acetate: methanol $(20: 80 \mathrm{v} / \mathrm{v})$ gives the better response, but poor peak shape was observed. A mobile phase of $0.1 \%$ formic acid in water in combination with methanol and acetonitrile with varying combinations were tried. Short length columns, such as Symmetry Shield RP18 ( 50 x $2.1 \mathrm{~mm}, 3.5 \mu \mathrm{m})$, Inertsil ODS-2V ( $50 \times 4.6 \mathrm{~mm}$, $5 \mu \mathrm{m})$, Hypurity C18 (50 x $4.6 \mathrm{~mm}, 5 \mu \mathrm{m})$ and Hypurity Advance ( $50 \times 4.0 \mathrm{~mm}, 5 \mu \mathrm{m})$, Xbridge C18, 50x4.6 mm $5 \mu \mathrm{m}$ were tried during the method development. After a sequence of trials, chromatographic separation was achieved with $5 \mathrm{mM}$ ammonium acetate in combination with methanol (30:70 v/v), gave the best peak shape and low baseline noise was observed using the Zorbax SB-C18 analytical column (80 , $4.6 \mathrm{~mm}$ X $75 \mathrm{~mm}, 3.5 \mu \mathrm{m}$ ). The total analysis time was $13 \mathrm{~min}$ and flow rate was set to $0.6 \mathrm{~mL} / \mathrm{min}$. The temperature was set to $40^{\circ} \mathrm{C}$ for the 
Table 1: Optimized mass parameters of Venetoclax and Venetoclax-D8.

\begin{tabular}{|c|c|c|c|c|c|c|c|c|}
\hline \multicolumn{9}{|c|}{ Molecular ion to production transitions used for quantification } \\
\hline \multirow{2}{*}{ Compound } & \multicolumn{4}{|c|}{ Molecular ion } & \multicolumn{4}{|c|}{ Product ion } \\
\hline & \multicolumn{4}{|c|}{$(\mathrm{m} / \mathrm{z})$} & \multicolumn{4}{|c|}{$(\mathrm{m} / \mathrm{z})$} \\
\hline VX & \multicolumn{4}{|c|}{$868.12[\mathrm{M}+\mathrm{H}]^{+}$} & \multicolumn{4}{|c|}{$321.54^{+}$} \\
\hline \multirow[t]{4}{*}{ VXD8 } & \multicolumn{4}{|c|}{$876.90[\mathrm{M}+\mathrm{H}]^{+}$} & \multicolumn{4}{|c|}{$329.70^{+}$} \\
\hline & \multirow{2}{*}{\multicolumn{4}{|c|}{$\begin{array}{l}\text { Source dependent parameters } \\
\text { (psi) }\end{array}$}} & \multirow{2}{*}{\multicolumn{4}{|c|}{$\begin{array}{l}\text { Compound dependent parameters } \\
\text { (Volts) }\end{array}$}} \\
\hline & & & & & & & & \\
\hline & CUR gas & $\begin{array}{l}\text { CAD } \\
\text { gas }\end{array}$ & $\begin{array}{c}\text { Nebulizer } \\
\text { gas }\end{array}$ & $\begin{array}{l}\text { Heater } \\
\text { gas }\end{array}$ & EP & DP & CE & CXP \\
\hline vX & 20 & 4 & 20 & 40 & 10 & 30 & 35 & 12 \\
\hline VXD8 & 20 & 4 & 20 & 40 & 10 & 28 & 30 & 12 \\
\hline \multicolumn{9}{|c|}{ Common mass parameters for VX, VXD8 } \\
\hline Ion spray voltage & \multicolumn{8}{|c|}{5500 volts } \\
\hline Temperature & \multicolumn{8}{|c|}{$400^{\circ} \mathrm{C}$} \\
\hline Scan type & \multicolumn{8}{|c|}{ MRM } \\
\hline Dwell time & \multicolumn{8}{|c|}{$500 \mathrm{msec}$} \\
\hline Type of ionization & \multicolumn{8}{|c|}{ Electro spray ionization (ESI) } \\
\hline
\end{tabular}

Table 2: Calibration curve details of Venetoclax.

\begin{tabular}{cccc}
\hline Nominal concentration $(\mathrm{pg} / \mathrm{mL})$ & $\begin{array}{c}\text { Concentration measured } \\
(\mathrm{pg} / \mathrm{mL})\end{array}$ & $\begin{array}{c}\text { Precision } \\
(\mathrm{CV} \%)\end{array}$ & $\begin{array}{c}\text { Accuracy } \\
\%\end{array}$ \\
\hline 10.0 & $9.9 \pm 0.1$ & 3.04 & 103.76 \\
20.0 & $20.4 \pm 0.4$ & 1.05 & 95.14 \\
200.0 & $198.7 \pm 6.2$ & 1.71 & 99.44 \\
800.0 & $782.5 \pm 27.4$ & 2.73 & 102.2 \\
1500.0 & $1486.5 \pm 41.6$ & 3.93 & 100.77 \\
3000.0 & $2964.8 \pm 100.8$ & 0.79 & 100.65 \\
4500.0 & $4478.9 \pm 107.5$ & 2.9 & 99.47 \\
6000.0 & $5863.4 \pm 111.4$ & 0.94 & 99.47 \\
7500.0 & $7469.6 \pm 283.8$ & 0.02 & 101.83 \\
10000.0 & $9869.6 \pm 213.8$ & 1.11 & 103.94 \\
\hline
\end{tabular}

Values are expressed as (mean \pm SD) $(n=5)$. SD: Standard deviation, $C V$ : Coefficient of variation

Table 3: Precision and Accuracy (analysis with spiked plasma samples at three different concentrations).

\begin{tabular}{|c|c|c|c|c|c|c|}
\hline \multirow[b]{2}{*}{$\begin{array}{c}\text { Nominal } \\
\text { concentration } \\
(\mathrm{pg} / \mathrm{mL})\end{array}$} & \multicolumn{3}{|c|}{ Intra batch/ Within-run $(n=6)$} & \multicolumn{3}{|c|}{ Inter batch/ Between-run $(n=30)$} \\
\hline & $\begin{array}{c}\text { Concentration } \\
\text { measured }(\mathrm{pg} / \mathrm{mL})\end{array}$ & $\begin{array}{l}\text { Precision } \\
\text { (\%RSD) }\end{array}$ & $\begin{array}{c}\text { Accuracy } \\
\%\end{array}$ & $\begin{array}{c}\text { Concentration } \\
\text { measured } \\
(\mathrm{pg} / \mathrm{mL})\end{array}$ & Precision (\%RSD) & $\begin{array}{c}\text { Accuracy } \\
\%\end{array}$ \\
\hline 300.0 & $28.9 \pm 0.5$ & 7.7 & 96.3 & $29.4 \pm 0.7$ & 6.2 & 98 \\
\hline 3500.0 & $3426.7 \pm 95.9$ & 6.35 & 97.9 & $3512.4 \pm 119.4$ & 8.5 & 100.4 \\
\hline 8000.0 & $7896.4 \pm 189.5$ & 5.7 & 98.7 & $7945.6 \pm 166.9$ & 5.95 & 99.3 \\
\hline
\end{tabular}

Values are expressed as (mean \pm SD). SD: Standard deviation, RSD: Relative standard deviation

Table 4: Stability of Venetoclax in human plasma samples.

\begin{tabular}{|c|c|c|c|c|c|c|c|c|}
\hline \multirow{3}{*}{$\begin{array}{c}\text { Nominal } \\
\text { concentration } \\
(\mathrm{pg} / \mathrm{mL})\end{array}$} & \multicolumn{2}{|c|}{$\begin{array}{l}\text { Room temperature } \\
\text { stability }\end{array}$} & \multicolumn{2}{|c|}{$\begin{array}{c}\text { Autosampler sample } \\
\text { stability }\end{array}$} & \multicolumn{2}{|l|}{$\begin{array}{l}\text { Long term } \\
\text { stability }\end{array}$} & \multicolumn{2}{|c|}{ Freeze and thaw stability } \\
\hline & $72 \mathrm{~h}$ & & $78 \mathrm{~h}$ & & 71 days & & Cycle 3 ( & \\
\hline & $\begin{array}{l}\text { Concentration } \\
\text { measured } \\
(\mathrm{pg} / \mathrm{mL})\end{array}$ & $\% \mathrm{CV}$ & $\begin{array}{c}\text { Concentration } \\
\text { measured } \\
(\mathrm{pg} / \mathrm{mL})\end{array}$ & $\% \mathrm{CV}$ & $\begin{array}{l}\text { Concentration } \\
\text { measured } \\
(\mathrm{pg} / \mathrm{mL})\end{array}$ & $\% \mathrm{CV}$ & $\begin{array}{l}\text { Concentration } \\
\text { measured } \\
(\mathrm{pg} / \mathrm{mL})\end{array}$ & $\% \mathrm{CV}$ \\
\hline 30.0 & $29.5 \pm 0.6$ & 7.9 & $29.2 \pm 0.8$ & 3.35 & $28.6 \pm 0.9$ & 8.74 & $28.9 \pm 0.9$ & 10.7 \\
\hline 8000.0 & $7868.1 \pm 133.8$ & 5.2 & $7937.7 \pm 150.8$ & 1.09 & $7896 \pm 213.2$ & 6 & $7958.3 \pm 191.0$ & 6.19 \\
\hline
\end{tabular}

Values are expressed as $($ mean \pm SD) $(n=6)$. SD: Standard deviation, $C V$ : Coefficient of variance 
column oven. The sample volume for the injection into mass spectrometry was adjusted to $10 \mu \mathrm{L}$ for better ionization and chromatography. Utilization of stable isotope-labeled (VXD8) or suitable analog drugs as an internal standard proves helpful when a significant matrix effect is possible. The peak elution times 6.1, 6.2 $\mathrm{min}$ (VX, VXD8) respectively. LLE is suitable for extraction of drug and IS. $10 \mathrm{mM}$ potassium dihydrogen phosphate buffer and methyl tertiary butyl ether served as good extraction solvent. Auto sampler wash is optimized as $50 \%$ methanol. Venetoclax gave more response in positive ion mode as compare to the negative ion mode. To get high intense productions source dependent parameters were optimized like Heater gas flow 40 psi, nebulizer gas flow 20 psi and curtain gas flow 20 psi, ion spray voltage $5500 \mathrm{~V}$, and temperature $400^{\circ} \mathrm{C}$. The compound dependent parameters such as the declustering potential (DP), entrance potential (EP), collision energy (CE), cell exit potential (CXP) were optimized during tuning as 30,10 , 35, $12 \mathrm{eV}$ for Venetoclax and Venetoclax-D8, respectively. The collision activated dissociation (CAD) gas was set at 4 psi using nitrogen gas. Quadrupole-1 and quadrupole-3 were both maintained at a unit resolution and dwell time was set at $200 \mathrm{~ms}$ for analyte and IS. The predominant peaks in the primary ESI spectra of VX and VXD8 correspond to the $\mathrm{M}+\mathrm{H}^{+}$ions at $\mathrm{m} / \mathrm{z} 868.12$ and 876.9 respectively which were depicted in Figure 2 and 3. Productions of VX and VXD8 scanned in quadrupole- 3 after a collision with nitrogen in quadrupole-2 had $\mathrm{m} / \mathrm{z}$ of 321.54 and 329.70 respectively shown in Table 1 .

A thorough and complete method validation of Venetoclax in human plasma was performed as per US FDA guidelines. The selectivity (Matrix screening) and sensitivity of the method towards endogenous plasma matrix components was assessed in ten lots (five $\mathrm{K}_{2}$ EDTA plasma lots, two hemolyzed lots, two lipimic lots and one heparinised lot) of blank human plasma, out of which six lots free from interferences. This was done to estimate the extent to which endogenous plasma components contribute towards interference at the retention time of analyte and IS. The analysis of VX and VXD8 using MRM function was highly selective with no interfering compounds. The Calibration curve details, by plotting the peak area ratios of analyte to IS versus the nominal concentrations of VX from the range of $10.0-10000.0 \mathrm{pg} / \mathrm{mL}$. The calibration curve had a coefficient correlation $\left(r^{2}\right)$ was $\geq 0.9997$. Matrix effect was assessed by using Six extracted blank plasma samples in three replicates spiked with the un-extracted concentration of mid QC $(3500.00 \mathrm{pg} / \mathrm{mL})$ were compared with un-extracted standards of the same concentration. The precision of the matrix factor should be less than $\% \mathrm{CV} \leq 15 \%$. The Precision and Accuracy of VX (analysis with spiked plasma samples at three different concentrations - 30.0, 3500.0 and $8000.0 \mathrm{pg} / \mathrm{mL}$ ) in six replicates on the same day (Intraday) and five different days (Inter day). The \% RSD should be no greater than 15\% for LQC, MQC and HQC and within $20 \%$ for LLQC. Mean \% Accuracy should be $100 \pm 15 \%$, except LLOQ for which it is $100 \pm 20 \%$. The extraction recovery was done in sextuplicate by comparing the extracted QC standards with un-extracted QC standards at three different concentrations $(30.00,3500.00$ and $8000.00 \mathrm{pg} / \mathrm{mL})$, the mean coefficient of variation for LQC, MQC and HQC shall not exceed $25 \%$. The mean coefficient of variation for IS shall not exceed $25 \%$. Stability of Venetoclax in human plasma samples done at each level of six aliquots for lower and higher concentrations (Bench top stability $(72 \mathrm{~h})$, Freeze-thaw Stability $\left(-30^{\circ} \mathrm{C}\right.$, after $3^{\text {rd }}$ cycle $)$, Autosampler stability $\left(2-8^{\circ} \mathrm{C}, 78 \mathrm{~h}\right)$ and Long-term stability $\left(-30^{\circ} \mathrm{C}, 71\right.$ Days). The $\% \mathrm{RSD} \leq 15 \%$, except LLOQ for which it is $\leq 20 \%$ and the mean \%accuracy should be $100 \pm 15 \%$ showed in Table 4 . Hence Stability of VX was successfully established.

\section{CONCLUSION}

The proposed method described here was five folds higher sensitive and has significant advantages over previously described methods. The main drawbacks for previous techniques are long run analysis for stability, sample preparations are tedious, expensive and using organic solvents in mobile phases and extract preparation of biological samples. Moreover plasma interferences, it may associate with the ion suppression, affecting adduct formation and assay sensitivity is decreased. Hence the methods are labour-intensive and time consuming.

The bioanalytical method described here is fast, sensitive, rugged and reproducible. The analyte (VX) was compared with deuterated internal standard (VXD8). The developed method is simple and efficient and can be successfully used in pharmacokinetics studies as well as in the monitoring of the investigated analyte in body fluids.

\section{CONFLICT OF INTEREST}

The authors declare no conflicts of interest.

\section{ABBREVIATIONS}

HPLC-MS/MS: High Performance Liquid Chromatography/ Tandem Mass Spectrometry; ESI: Electron Spray Ionization; MRM: Multiple Reaction Monitoring; VX: Venetoclax; VXD8: Venetoclax-D8; IS: Internal Standard; BCL-2: B-Cell Lymphoma 2; CLL: Chronic Lymphocytic Leukemia; SLL: Small Lymphocytic Lymphoma; SB: Stable Bond; U.S-FDA: United State Food and Drug Administration; K2-EDTA: Di Potassium Ethylene Diamine tetra Acetic acid; DP: Declustering Potential; FP: Focussing Potential; EP: Entrance Potential; CE: Collision Cell Entrance Potential; CXP: Collision Cell Exit Potential; CAD: Collisionally Activated Dissociation; QC: Quality control; LLE: Liquid-Liquid Extraction; LLOQ: Lower Limit of Quantification; RSD: Relative Standard Deviation; S/N: Signal to Noise Ratio; ODS: Octa Decyl Silane.

\section{REFERENCES}

1. Zenz T, Mertens D, Kuppers R, Dohner H, Stilgenbauer S. From pathogenesis to treatment of chronic lymphocytic leukaemia. Nat Rev Cancer. 2010;10(1):37-50.

2. Jaglowski S, Jones JA. Choosing first-line therapy for chronic lymphocytic leukemia. Expert Rev Anticancer Ther. 2011;11(9):1379-90.

3. Shenoy PJ, Malik N, Sinha R, Nooka A, Nastoupil LJ, Smith M, et al. Racial differences in the presentation and outcomes of chronic lymphocytic leukemia and variants in the United States. Clin Lymphoma Myeloma Leuk. 2011;11(6):498-506.

4. Souers AJ, Leverson JD, Boghaert ER, Ackler SL, Catron ND, Chen J, et al. ABT-199, a potent and selective BCL-2 inhibitor, achieve antitumor activity while sparing platelets. Nat Med. 2013;19(2):202-8.

5. Itchaki G, Brown JR. The potential of Venetoclax (ABT-199) in chronic lymphocytic leukemia. Ther Adv Hematol. 2016;7(5):270-87.

6. Roberts AW, Stilgenbauer S, Seymour JF, Huang DCS. Venetoclax in patients with previously treated chronic lymphocytic leukemia. Clin Cancer Res. 2017;23(16):4527-33.

7. Seymour JF, Ma S, Brander DM, Choi MY, Barrientos J, Davids MS, et al. Venetoclax plus rituximab in relapsed or refractory chronic lymphocytic leukaemia: a phase 1b study. Lancet Oncol. 2017;18(2):230-40.

8. Courtney D, Daniel P, Keith P, Michael JT, Anthony L, Mark F, et al. A phase 1b study of Venetoclax (ABT 199/GDC-0199) in combination with decitabine or azacitidine in treatment-naive patients with acute myelogenous leukemia who are $\geq 65$ years and not eligible for standard induction therapy. Blood. 2015;126:327.

9. Moreau P, Chanan KA, Roberts AW, Agarwal AB, Facon T, Kumar S, et al. Promising efficacy and acceptable safety of Venetoclax plus bortezomib and dexamethasone in relapsed/refractory MM. Blood. 2017;130(22):2392-400.

10. Konopleva M, Pollyea DA, Potluri J, Chyla B, Hogdal L, Busman T, et al. Efficacy and Biological Correlates of Response in a Phase II Study of Venetoclax Monotherapy in Patients with Acute Myelogenous Leukemia. Cancer Discov. 2016;6(10):1106-17.

11. Agarwal SK, Hu B, Chien D, Wong SL, Salem AH. Evaluation of Rifampin's 
Transporter Inhibitory and CYP3A Inductive Effects on the Pharmacokinetics of Venetoclax, a Bcl-2 Inhibitor: Results of a Single- and Multiple-dose Study. J Clin Pharmacol. 2016;56(11):1335-43.

12. Cervantes GF, Lamothe B, Woyach JA, Wierda WG, Keating MJ, Balakrishnan K, et al. Pharmacological and Protein Profiling Suggests Venetoclax (ABT-199) as Optimal Partner with Ibrutinib in Chronic Lymphocytic Leukemia. Clin Cancer Res. 2015;21(16):3705-15

13. Stilgenbauer S, Eichhorst B, Schetelig J, Coutre S, Seymour JF, Munir T, et al.
Venetoclax in relapsed or refractory chronic lymphocytic leukaemia with $17 p$ deletion: a multicentre, open-label, phase 2 study. Lancet Oncol. 2016;17(6):768-78.

14. Liu H, Michmerhuizen MJ, Lao Y, Wan K, Salem AH, Sawicki J, et al. Metabolism and Disposition of a Novel Bcl-2 Inhibitor Venetoclax in Humans and Characterization of its Unusual Metabolites. Drug Metab Dispos. 2017;45(3):294-305.

15. Guidance for industry: bioanalytical method validation, U.S. Department of health and human services, food and drug administration, center for drug evaluation and research (CDER), Center for biologics evaluation and research (CBER). 2001.

Article History: Submission Date : 07-03-2018; Revised Date : 02-07-2018; Acceptance Date : 06-08-2018.

Cite this article: Inturi S, Yejerla RK, Jujjuru NSK, Avula PR. Evaluation of Deuterium-Labeled Internal Standard for the Measurement of Venetoclax by HPLC-

ESI -Tandem Mass Spectrometry. J Young Pharm. 2018;10(4):392-8. 